\title{
Toxic polyneuropathy due to glue sniffing
}

\author{
IKUO GOTO, MUTSURO MATSUMURA, NAOHIDE INOUE, \\ YOSHIYUKI MURAI, KENSHIRO SHIDA, TETSUJI SANTA, \\ AND YOSHIGORO KUROIWA
}

From the Department of Neurology, Neurological Institute, Faculty of Medicine, Kyushu University, Fukuoka, Japan

SYNOPSIS Four cases of toxic polyneuropathy due to glue-sniffing were reported. Neurological examination revealed motor predominant mixed type polyneuropathy. The cause of polyneuropathies in these cases was considered to be due to the inhalation of the vaporized elements of the adhesive agent, which contain mainly n-hexane and toluene. $\mathrm{N}$-hexane is considered to be chiefly responsible for the polyneuropathy, though toluene also could have some influence on the illness.

Recently, inhalation of glue vapours (trade name: Bond or Cemedain) has become popular among teenagers in Japan. There have been reports of n-hexane polyneuropathy as a result of industrial exposure (Wada et al., 1965; Yamada, 1967; Sobue et al., 1968; Yamamura, 1969; Herskowitz et al., 1971), but few reports on glue sniffing as a cause of peripheral nerve involvement. The purpose of this paper is to describe four cases of toxic polyneuropathy due to glue sniffing.

\section{CASE 1}

An 18 year old female had a history of frequent inhalation of the volatile gas emitted by the adhesive agent Bond G17. She continued this practice for nine months, consuming from 50 to $100 \mathrm{~g}$ of the agent every night from January to the middle of September 1971, when she first noticed weakness of the right leg. A week later she was aware of weakness and numbness of both upper and lower extremities and these symptoms were slowly progressive. She was admitted to our hospital on 11 November 1971.

General physical examination was negative. Neurological examination revealed flaccid quadriplegia with moderate to severe muscular atrophies, predominantly in the distal parts of all extremities. She could not move her fingers, wrists, and lower limbs. There was no fasciculation. Deep reflexes were absent in all extremities. She showed a glove and stocking type sensory impairment extending to the elbows and above the iliac crest, and vibration sense was also slightly diminished below the iliac. crest.

Normal results were obtained for urinalysis, com $\rho$ plete blood count, blood urea nitrogen, venereab 의 disease research laboratory test (VDRL), serun $\vec{P}$ cholesterol, serum protein electrophoresis, serum $气$ electrolytes, a glucose tolerance test, electrocardiog

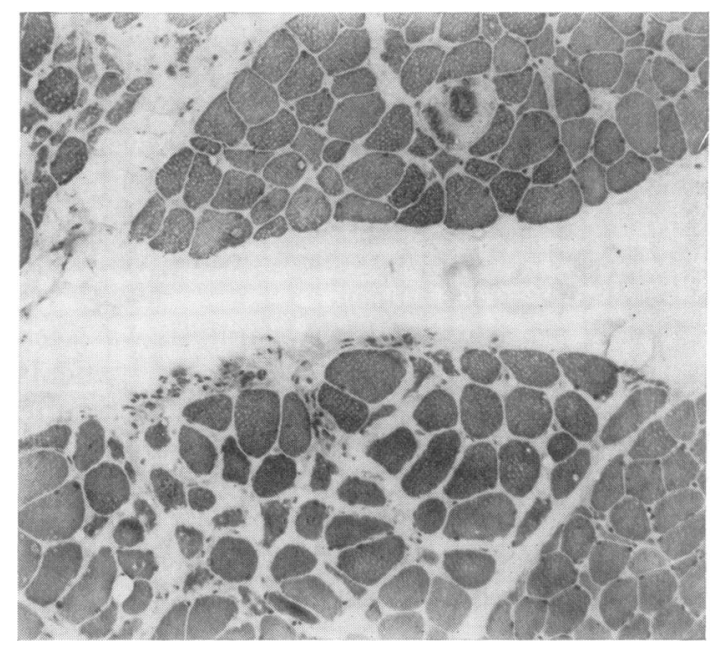

FIG. 1. Case 1. Muscle biopsy specimen. There is a moderate increase in connective tissue and fatty tissue. The mild variation in diameter of muscle fibres is seen. Occasionally degenerative muscle fibres are also seen. Transverse section. $H$ and $E, \times 84$. 
gram and radiographs of the chest. The serum level of creatine phosphokinase (CPK) was 36.9 units (normal level: less than 19 units). The cerebrospinal fluid protein concentration was $22 \mathrm{mg} / \mathrm{dl}$ with two lymphocytes per $\mathrm{mm}^{3}$. Electromyography revealed fibrillation potentials in the quadriceps femoris, tibialis anterior, and gastrocnemius muscles and complex motor unit action potentials in the interosseous muscles of the hands. The motor conduction velocities were $27.0 \mathrm{~m} / \mathrm{s}$ in the ulnar nerve (normal: above $46.0 \mathrm{~m} / \mathrm{s}$ ) and $26.6 \mathrm{~m} / \mathrm{s}$ in the tibial nerve (normal: above $37.0 \mathrm{~m} / \mathrm{s}$ ). No sural nerve action potential could be detected.

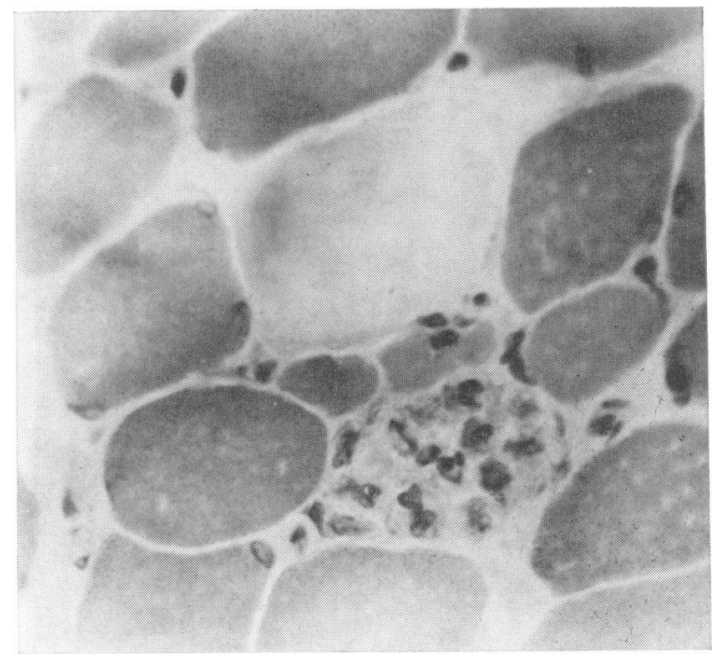

FIG. 2. Case 1. Muscle biopsy specimen. Necrotic fibres and myophagia are seen. Transverse section. $H$ and $E, \times 400$.

\section{CASE 2}

This 18 year old female was the identical twin of case 1 . The present illness was similar to that of her sister except for less frequent inhalation. She had inhaled about $20 \mathrm{~g}$ per week for eight months and 20 to $40 \mathrm{~g}$ of the adhesive agent every day from the end of July to 20 September 1971.

General physical examination was normal. Neurological examination revealed wasting of the muscles of the arms and legs. The lower extremities were affected more than the upper extremities, with prominent weakness of the proximal muscles. She showed a steppage gait. Gowers's sign was positive. There was no fasciculation. Deep reflexes were absent in all extremities. Touch and pinprick sensa- tions were slightly impaired in a stocking distribution extending to below the knee. Position and vibration senses were normal.

Laboratory examinations revealed a normal blood count, blood urea nitrogen, urinalysis, VDRL test, electrolytes, glucose tolerance test, liver function test, and serum CPK. Radiographs of the chest and electrocardiogram were normal. Electroencephalography was within normal limits with slightly disorganized background activities. An electromyogram (EMG) demonstrated a pattern of neurogenic atrophy with long duration motor unit potentials in the quadriceps femoris and gastrocnemius muscles. The motor nerve conduction velocities were 39.2 $\mathrm{m} / \mathrm{s}$ in the ulnar nerve and $30.7 \mathrm{~m} / \mathrm{s}$ in the tibial nerve, both below normal.

\section{CASE 3}

The patient, a 22 year old single male, had been addicted to glue sniffing since the age of 19 years. He averaged $50 \mathrm{~g}$ per month for one year and would inhale $50 \mathrm{~g}$ of glue (trade name: Cemedain Contact) every other day from March to July in 1971 and from 1 to 31 January in 1972. He became aware of numbness of the lower extremities at the end of March 1972. In spite of having discontinued inhalation of glue, weakness in all extremities was gradually progressive. He noticed difficulty in speaking and became unable to turn over in bed. He was hospitalized on 25 April.

General physical examination showed no abnormalities except for emaciation. Neurological examination revealed moderate to marked atrophy and weakness in all extremities with foot and wrist drop. Deep reflexes were absent in all limbs, and showed a glove and stocking type sensory impairment in all extremities. Vibration and joint sensations were intact. Routine laboratory studies showed normal values. Cerebrospinal fluid contained $30 \mathrm{mg} / \mathrm{dl}$ of protein with two lymphocytes per $\mathrm{mm}^{3}$. Motor nerve conduction velocities were $33.4 \mathrm{~m} / \mathrm{s}$ in the ulnar nerve and $28.5 \mathrm{~m} / \mathrm{s}$ in the tibial nerve.

\section{CASE 4}

A 25 year old female indulged in glue sniffing, Bond G-10, about $1,000 \mathrm{~g}$ monthly from October 1971 to April 1972, when she developed difficulty in walking. Although she discontinued the inhalation, the gait disturbance progressed slowly and she also noticed weakness of hands and fingers. On physical examination she was well nourished. Cranial nerves were intact. There was severe distal weakness of all four limbs with mild muscular atrophy. No fasciculations were noted. Deep reflexes were absent in the lower 


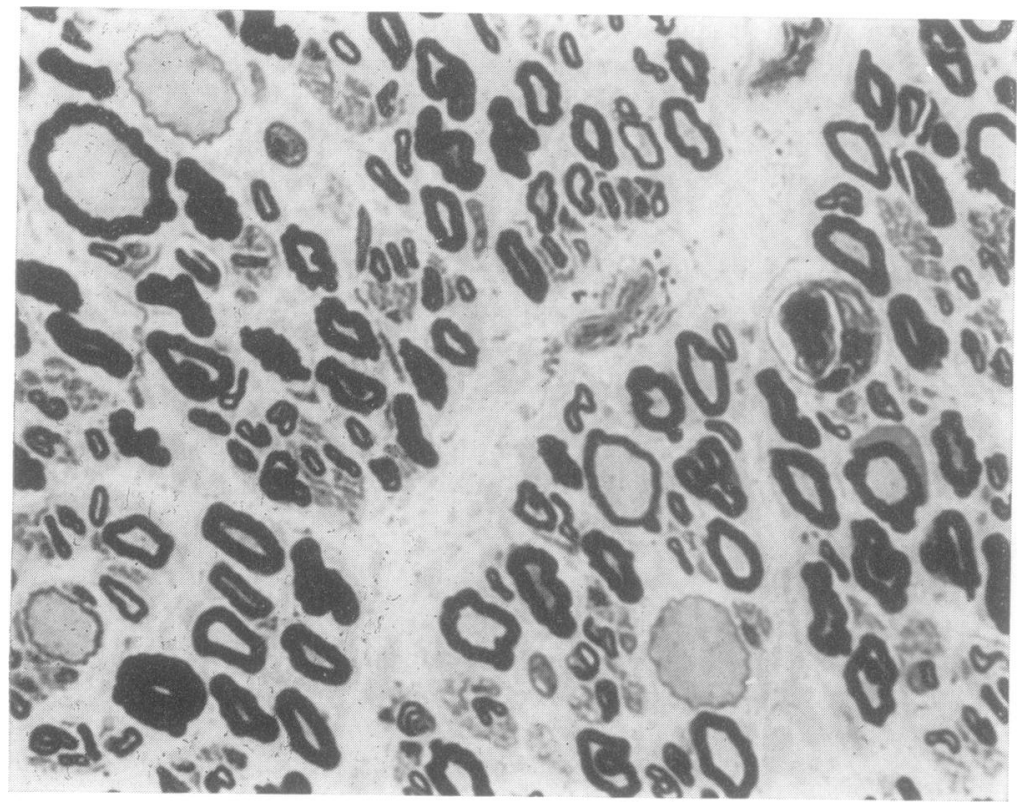

FIG. 3. Case 1. Fascicular biopsy of sural nerve. Thin walled myelinated fibres are seen. Transverse section. Toluidine blue, $\times 780$.

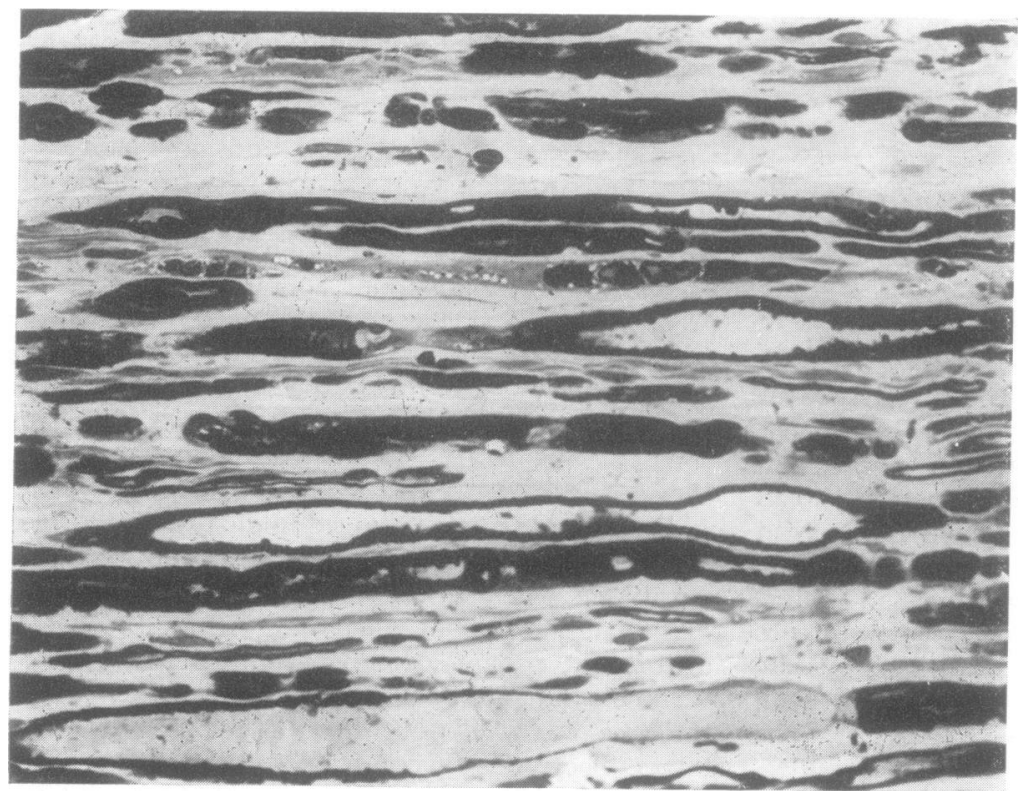

FIG. 4. Case 1. Longitudinal section of sural nerve. In lower part, there are myelinated nerve fibres showing irregularities of myelin sheath and axonal swelling. Toluidine blue, $\times 780$. 


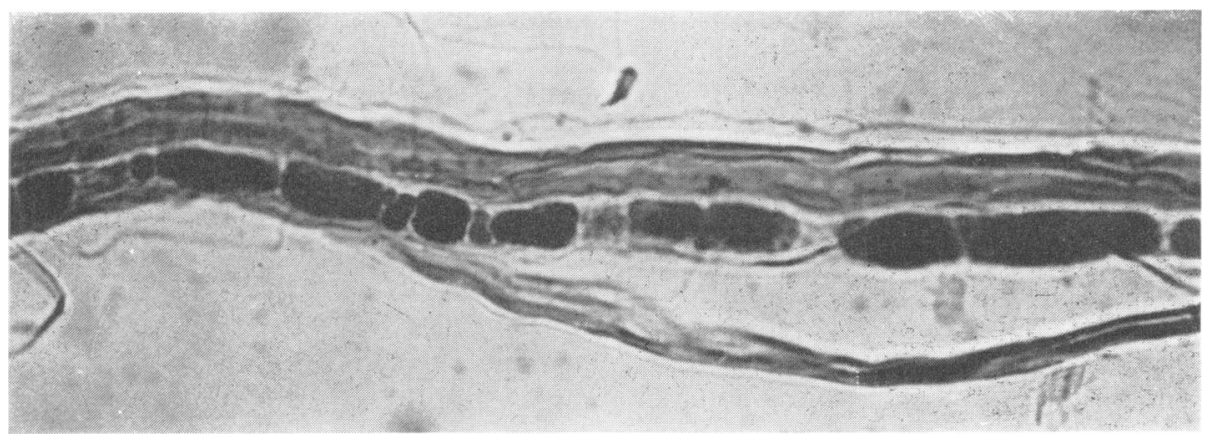

FIG. 5. Case 1. Teased myelinated fibres from sural nerve. The myelinated nerve fibre is broken up into myelin ovoids of various size. Osmium stain, $\times 420$.

limbs and hypoactive in the upper limbs. She had a slight sensory impairment of all modalities below the knees with stocking distribution.

HISTOLOGICAL EXAMINATION Biopsied specimens were obtained from the left fibularis brevis muscle in case 1 and 2, and the left quadriceps femoris muscle in case 3. Sural nerve biopsies were performed in case 1 and 2. A small piece of the muscle was fixed in formaldehyde solution, embedded in paraffin, and sections were stained with haematoxylin-eosin $(\mathrm{H}$ and $\mathrm{E}$ ). The second portion was rapidly frozen by dry ice, and used for the demonstration of dihydronicotinamide adenine dinucleotide dehydrogenase, ATP-ase, and acid phosphatase activities. Other sections were stained with modified Gomori's trichrome, $\mathrm{H}$ and $\mathrm{E}$, and PAS.

For nerve teasing methods, the tissues were fixed in osmium tetraoxide solution and then immersed in a glycerol-water solution. Other pieces of the nerves were embedded in Epon, and $1 \mu \mathrm{m}$ sections were stained with toluidine blue for light microscopic study.

Histological findings of biopsied muscles were as follows: in case 1 ; the muscle fibres ranged from 10 to $85 \mu \mathrm{m}$ with most of the fibres measuring $50 \mu \mathrm{m}$ in diameter. There was a mild increase in connective tissue. Approximately $6 \%$ of the fibres showed central nuclei. Some fibres showed marked degenerative changes with phagocytosis. Occasionally small groups of the small fibres were seen and atrophic fibres were of histochemical types 1 and 2 (Figs 1,2). In case 2 the diameter of the muscle fibres varied from 25 to $90 \mu \mathrm{m}$. There was no increase in the number of centrally located nuclei and there was a mild increase in connective tissue, but no marked degenerative change. Occasionally a small group of small fibres was seen. Normal distribution of fibres as to the histochemical type was preserved. On electronmicroscopic examination, some fibres showed focal myofibrillar degeneration which consisted of $\mathrm{Z}$ streaming and mitochondrial decrease, with no additional findings in cases 1 and 2 . In case 3 the histological findings showed similar changes except for type 2 fibre atrophy as in case 2 .

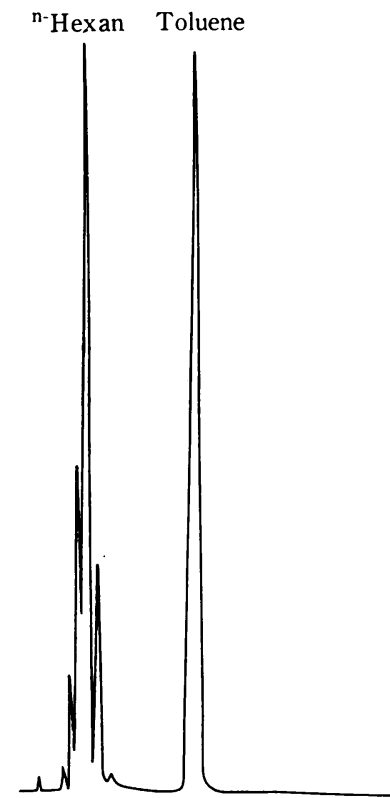

FIG. 6. Pattern of the vapourized elements of the adhesive agent, Bond G-17, by gas chromatography. Column: SE-30. Oven temperature: $30-150^{\circ} \mathrm{C}$. Programme rate: $7.5 \mathrm{C} / \mathrm{min}$. Injection block: $250^{\circ} \mathrm{C}$. Carrier gas: $N_{2}$. Flow rate: $2 \cdot 1 \mathrm{~kg} / \mathrm{cm}, 30 \mathrm{ml} / \mathrm{min}$. Attenuation: $20 \times 10$. Chart speed: $10 \mathrm{~mm} / \mathrm{min}$. 
Sural nerve biopsies showed normal fibre density and a histogram revealed a bimodal distribution in cases 1 and 2 . However, there was slight loss of fibres, especially in the larger fibres. There was axonal degeneration and segmental demyelination, more remarkable in case 1 than in case 2 (Figs 3, 4, 5).

CHEMICAL ANALYSIS OF ADHESIVE AGENT The adhesive agent Bond G-17 contains $30 \%$ of gum made from chloroprene, $25 \% \mathrm{n}$-hexane, $24 \%$ toluene, and $20 \%$ methyl-ethyl ketone. The vapourized elements of this adhesive agent contained the same amount of n-hexane and toluene by gas-chromatography (Fig. 6). The adhesive agent Bond G-10 contains $28 \%$ n-hexane and $30 \%$ toluene. The adhesive agent Cemedain Contact contains $18 \%$ n-hexane and $43 \%$ toluene.

COURSE Three of four cases could be followed up. Case 1, who inhaled a large amount of glue, showed almost complete flaccid paralysis of four extremities. However, the patient improved gradually, was able to walk six months after admission and was discharged with a mild difficulty in walking nine months after admission. Case 2, who inhaled a relatively small amount of glue, showed considerable improvement and returned to her daily life without any difficulty in walking four months after admission. Case 3 improved gradually and was able to walk without any difficulty six months after admission.

\section{DISCUSSION}

Weakness and sensory impairment of the extremities developed in seven to 30 months after glue sniffing in these four cases. Their symptoms were slowly progressive up to three months after stopping inhalation, and showed gradual improvement thereafter. Neurological examinations revealed mixed type polyneuropathy, predominantly motor, in these cases. Initial symptoms developed after inhalation of about 20,000 g of glue, Bond G-17 (about $5,000 \mathrm{~g}$ n-hexane and about 5,000 $\mathrm{g}$ toluene) in case 1; about 2,000 g of glue, Bond G-17 (about $500 \mathrm{~g}$ n-hexane and about $500 \mathrm{~g}$ toluene) in case 2; about $10,000 \mathrm{~g}$ of glue, Cemedain Contact (about 1,800 g n-hexane and about 4,300 $\mathrm{g}$ toluene) in case 3 ; and about $6,000 \mathrm{~g}$ of glue, Bond G-10 (about 1,700 g n-hexane and about $1,800 \mathrm{~g}$ toluene) in case 4 .

The symptoms in case 1 were the most severe of these four cases, and the symptoms in cases 3 and 4 were more severe than those of case 2 who inhaled less glue. Recovery in cases 1,3 , and 4 was slower than that of case 2 . These facts suggest that the severity of symptoms is dependent on the total dose of the inhaled glue. Several authors (Wada et al., 1965; Yamada, 1967; Sobue et al., 1968; Yamamura, 1969; Herskowitz et al., 1971) have described cases with n-hexane polyneuropathy which developed two to six months after exposure to $n$-hexane. Their patients showed progressive symptoms two to three months after exposure ceased. Initial symptoms included sensory impairment in all extremities of glove and stocking distribution. Our cases revealed mainly motor polyneuropathy, while n-hexane produces mainly mixed or sensory polyneuropathy. This difference between our cases and n-hexane polyneuropathy may be due to the presence of toluene in glue and/or the mode of exposure-that is, the difference between relatively longer inhalation time at lower gas concentrations in $n$-hexane polyneuropathy compared with a shorter inhalation period for a gas of higher concentration in our cases.

It is known that acute intoxication from toluene causes confusion, excitement, impairment of consciousness, and damage to the liver and haematopoietic organs (Baker and Tichy, 1953). Satran and Dodson (1963) reported one case of chronic toluene intoxication who showed electroencephalographic abnormality after 10 years of toluene sniffing. Grabski (1961) and Knox and Nelson (1966) first reported a case of long-term toluene inhalation that apparently led to cerebellar degeneration. O'Brien et al. (1971) reported a patient who had hepatorenal damage from toluene inhalation. However, peripheral nerve damage was not reported. Lately, Heuser (1968) reported the first case of polyneuropathy due to toluene sniffing. His patient showed tremor, muscle atrophies, and weakness in the extremities. Fabre et al. (1955) described motor weakness of the lower limbs of dogs after chronic toluene exposure. Matsumoto (1971) reported a decrease of motor nerve conduction velocities in rats after one year's exposure to $200 \mathrm{ppm}$ toluene. Therefore, chronic toluene intoxication may cause peripheral nerve damage.

Though n-hexane had been considered to be chiefly responsible for polyneuropathy, toluene also seems to affect the peripheral nerve as 
witnessed by our four cases who, moreover, showed no other symptoms and signs of toluene poisoning such as impairment of the hepatic or haematopoietic systems.

This study was supported by a grant from Special Project of Toxic Neurological Diseases, the Ministry of Education, Japan. The authors wish to thank Drs Ohta and Ohnishi for their advice.

\section{REFERENCES}

Baker, A. B., and Tichy, F. Y. (1953). The effects of the organic solvents and industrial poisonings on the central nervous system. Association for Research in Nervous and Mental Diseases, 32, 475-505.

Fabre, R., Truhaut, R., Laham, S., and Peron, M. (1955). Recherches toxicologiques sur les solvants de remplacement du benzène; Étude du toluène. Archives des Maladies Professionelles, de Médecine du Travail et de Sécurité Sociale, 16, 197-215.

Grabski, D. A. (1961). Toluene sniffing producing cerebellar degeneration. American Journal of Psychiatry, 118, 461-462.

Herskowitz, A., Ishii, N., and Schaumburg, H. (1971). $\mathrm{N}$-hexane neuropathy. A syndrome occurring as a result of industrial exposure. New England Journal of Medicine, 285, 82-85.

Heuser, M. (1968). Toluolsucht. Medizinische Klinik, 63, $1888-1890$.

Knox, J. W., and Nelson, J. R. (1966). Permanent encephalopathy from toluene inhalation. New England Journal of Medicine, 275, 1494-1496.

Matsumoto, T. (1971). Experimental studies on the chronic toluene poisoning. 2. Electrophysiological changes of peripheral neuromuscular function in the rats exposed to toluene. Japanese Journal of Industrial Health, 13, 399-407.

O'Brien, E. T., Yeoman, W. B., and Hobby, J. A. E. (1971). Hepatorenal damage from toluene in a "glue sniffer". British Medical Journal, 2, 29-30.

Satran, R., and Dodson, V. N. (1963). Toluene habituation. Report of a case. New England Journal of Medicine, 268 , 719-721.

Sobue, I., Yamamura, Y., Ando, K., Iida, M., and Takayanagi, T. (1968). n-Hexane polyneuropathy. Outbreak among vinyl sandal manufacturers. Clinical Neurology, 8, 393-403.

Wada, Y., Okamoto, S., and Takagi, S. (1965). Intoxication polyneuropathy following exposure to $\mathrm{n}$-hexane. Clinical Neurology, 5, 591-597.

Yamada, S. (1967). Intoxication polyneuritis in the workers exposed to n-hexane. Japanese Journal of Industrial Health, 9, 651-659.

Yamamura, Y. (1969). n-Hexane polyneuropathy. Folia Psychiatrica et Neurologica Japonica, 23, 45-57. 